\title{
Investigation of structure deformation using a 3D laser scanning technique
}

\author{
Ježi Rapcevič, Darius Popovas \\ Vilnius Gediminas Technical University, Sauletekio al. 11, 10223 Vilnius, Lithuania
}

\begin{abstract}
Structure deformation monitoring problem is widely discussed but not fully solved problem. It is possible to indentify problematic issues such as the particularity of the data, measurement speed, and the reliability of results. Traditionally, building movements are analyzed using precision levels and tachometers or other sensors. Small scale deformation monitoring using terrestrial laser scanning is gaining considerable attention mainly due to the high spatial resolution of the acquired data. This article is focuses on 3D laser scanning technique usage in building deformation monitoring. The comparison between 3D laser scanning and traditional monitoring results are compared and presented. Monitoring of structure over a period of time was also performed using both 3D laser scanning and traditional surveying techniques. Using 3D scanner data control could be extended to the whole structure instead of being limited to a few points. The results of this work indicates a strong potential of 3D laser scanning technique for deformation monitoring, however some issues influencing the feasibility of laser scanning for deformation monitoring also considered.
\end{abstract}

Keywords: Terestrial laser scanning; deformation monitoring; inclination of the structures.

\section{Introduction}

The construction and operation of buildings can result in a lot of the factors influencing the stability and durability of the structures, so it is necessary to know the vertical and horizontal deformation parameters. According to the Lithuanian Standards Board the vertical deformations of installations and structures whose parameters changes over the time should be monitored (LST EN 1997-1). To assess the deformation parameters and their variation in time the geodetic measurement methods are widely used. Measurements of selected parameters, which uniquely express the processes taking place in the quantitative and qualitative state of the buildings, needs to be performed [1]. Traditionally, the vertical deformations are monitored by performing a precise levelling, horizontal deformations using tacheometric measurements, and cracks and other visual changes using photogrammetric techniques [2].

In this article a relatively new, so far not been subject to widespread use, deformation determination method i.e. 3D laser scanning will be analysed [3,4]. The test object is St. Barbora's Chapel located near Musninkai village, which was measured with taheometer Leica TS30 and 3D scanner Leica C10. There were two sets of measurements performed in July 2012 and July 2103. The results of laser scanning will be compared with tacheometric measurements and as result the inclination of the chapel will be compared. According to measurements made the chapel's inclination dynamics also estimated.

\section{Description of the hardware and software}

St. Barbora chapel deformation measurements were carried out using a Leica TS30 total station and a terrestrial laser scanner Leica Scanstation C10. Measurement data was processed using several software packages, namely Leica Cyclone 7.0, and AutoCAD Civil 3D 2013. The main parameters of the equipment are presented in Table 1.

Corresponding author: Darius Popovas. E-mail address: darius.popovas@vgtu.lt

http://dx.doi.org/10.3846/enviro.2014.239

(C) 2014 The Authors. Published by VGTU Press. This is an open-access article distributed under the terms of the Creative Commons Attribution License, which permits unrestricted use, distribution, and reproduction in any medium, provided the original author and source are credited. 
Table 1. Main specifications of devices

\begin{tabular}{lll}
\hline Specifications & Leica TS30 & Leica Scanstation C10 \\
\hline Angle Measurement accuracy & $0.5^{\prime \prime}$ & $12^{\prime \prime}$ \\
Distance Measurement accuracy (Prism;non-prism) & $1 \mathrm{~mm} ; 2 \mathrm{~mm}$ & $4 \mathrm{~mm}$ \\
Measurement speed & $3 \mathrm{sec}$ & $5000 \mathrm{pps}$ \\
Distance measurement range (non prism) & $1.5-1000 \mathrm{~m}$ & $0,1-300 \mathrm{~m}$ \\
Compensator setting accuracy & $0.5 "$ & $1.5^{\prime \prime}$ \\
Compensator method & Centralized quadruple axis compensation & Dual-axis compensation \\
\hline
\end{tabular}

\section{Data acquisition}

After measuring with total station the three-dimensional coordinates of characteristic points of the chapel were calculated. Measurements were obtained from two stations using resection to compute the coordinates of the instrument with $1 \mathrm{~mm}$ accuracy. Measurements of characteristic points were performed in a way, which allows creating seven cross-sections (two in the chapel's lower and upper block parts and in addition on the roof at the top of the cross (see Picture 1). This measurement method is selected in order to investigate in more details chapel's inclination parameters, dynamic movements and their origins. The measurement results graphically processed using Autocad Civil package and the inclination calculated using the formulas (1-9) presented below.
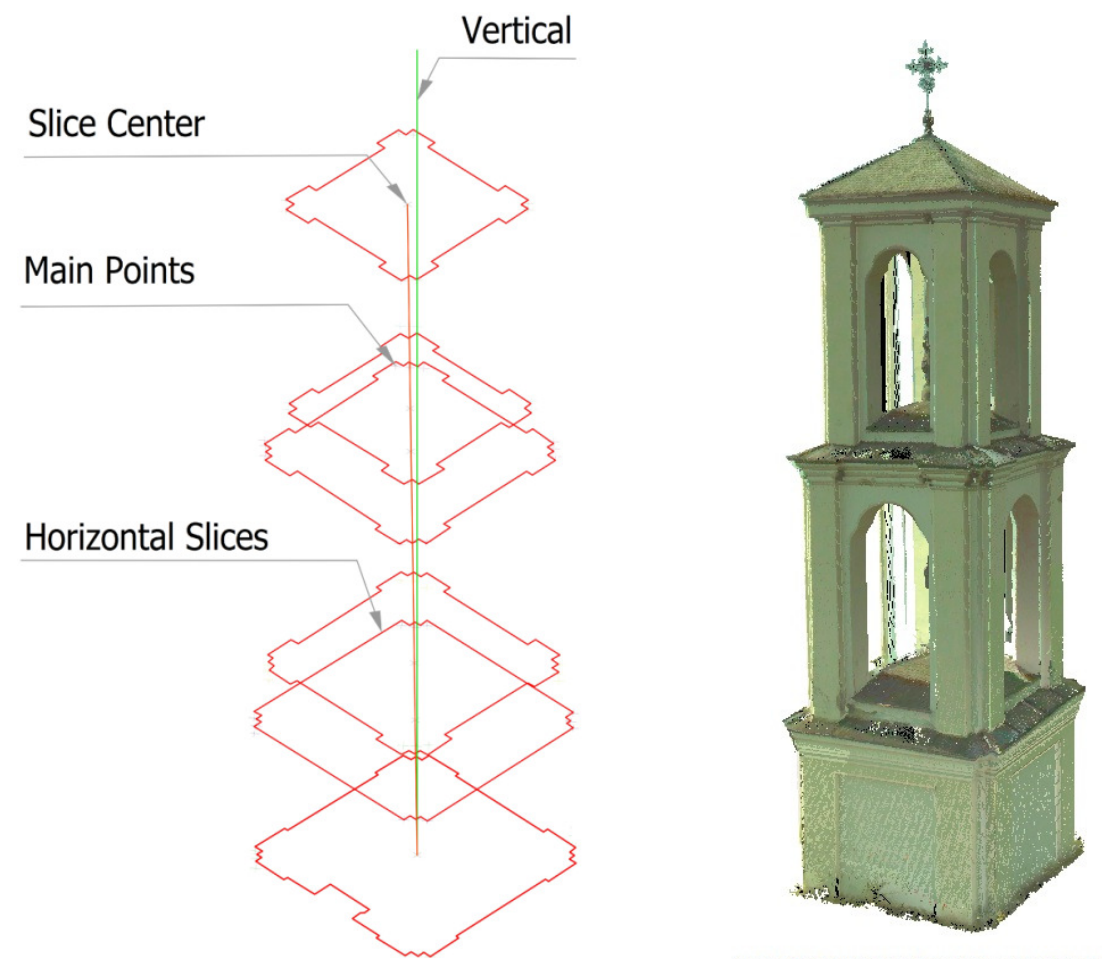

Fig. 1. Horizontal slice scheme of the chapel

Terrestrial laser scanner measurements results are of a three-dimensional point clouds representing the whole model of the chapel [5]. Object scan performed from three stations oriented to targets with known coordinates. By using Leica Cyclone software the three-dimensional model was created a horizontal cross-sections was made at the same heights as total station ones. An effective way of synthesizing the three dimensional information in vectorial and two dimensional output sections is to extract profiles from the model points: a very thin layer of the point cloud, delimited by a couple of parallel planes $[6,7]$. Using these cross-section further calculations and comparisons was made. 


\section{Description of the hardware and software}

The calculations were carried out in following order and using following formulas:

1. First the calculation of the cross-section centre coordinates are performed by using formulas:

$$
\begin{array}{r}
X_{c}=\frac{\sum_{i=1}^{n} X_{i}}{n}, \\
Y_{c}=\frac{\sum_{i=1}^{n} Y_{i}}{n}, \\
H_{c}=\frac{\sum_{i=1}^{n} H_{i}}{n},
\end{array}
$$

here $\mathrm{Xc}, \mathrm{Yc}, \mathrm{Hc}$ - the cross-sectional centre coordinates, $\mathrm{Xi}, \mathrm{Yi}, \mathrm{Hi}$ - coordinates of the measured points and $n-$ number of points coordinates in each cross-section.

It should be noted that scanned cross-sections heights $H_{c S K}$ is pre-set and it is equal to total station ones:

$$
H_{c S K}=H_{c}
$$

Also the points in scanner point cloud should be equally distributed in order to use formulas (1) and (2). This could be achieved by unifying point cloud or creating an equally distributed grid.

2. The calculations of the coordinate's changes in each cross-section in respect with the first (lowest) cross-section are performed:

$$
\begin{gathered}
\Delta X_{c_{i}}=X_{c_{i}}-X_{c_{1}} \\
\Delta Y_{c_{i}}=Y_{c_{i}}-Y_{c_{1}},
\end{gathered}
$$

where $\Delta X_{c_{i}}, \Delta Y_{c_{i}}$ - i-th cross-section centre shift in respect with 1st cross-section centre, $X_{c_{i}}, Y_{c_{i}}-$ the i-th cross-section center coordinates, $X_{c_{1}}, Y_{c_{1}}$ - the 1 st cross section centre coordinates.

3. The length of the shift vector $\Delta S_{i}$ is calculated in every cross section:

$$
\Delta S_{i}=\sqrt{\Delta X_{c_{i}}^{2}+\Delta Y_{c_{i}}^{2}}
$$

4. Estimation of the directional angle of the shift vector is performed:

$$
\begin{gathered}
\alpha=I F\left(\arctan \left(\Delta Y_{c_{i}} / \Delta X_{c_{i}}\right)>0\right) ; \operatorname{TRUE}\left(\arctan \left(\Delta Y_{c_{i}} / \Delta X_{c_{i}}\right)\right. \\
F A L S E\left(\arctan \left(\Delta Y_{c_{i}} / \Delta X_{c_{i}}\right)+360 .\right.
\end{gathered}
$$

5. And inclination angle $\beta$ of the chapel is estimated using formula:

$$
\beta=\tan \left(\Delta S_{i} /\left(H_{c_{i}}-H_{c_{1}}\right)\right) \text {. }
$$

The above formulas were used to calculate the deformation parameters of the chapel from total station and terrestrial laser scanner data.

\section{Overlie of the results}

The results of the processed measurements are presented in Tables $2-4$. The shifts of the different cross-sections in the X and Y directions from 2012 and 2013 measurements are presented. The inclination differences derived from the total station and terrestrial 3D scanner measurements are presented in Table 5. The dynamic of the ongoing deformation is estimated.

Chapel deformation parameters from 2012 laser scanning measurements are presented in Table 2. We see that the center of cross-section no. 6 is shifted by $33.4 \mathrm{~cm}$ in respect with cross-section no.1. That gives an inclination of the chapel by $1.5931^{\circ}$. The cross at the top of the chapel is marked C, however it is not used in any computations because of instability. 
Table 2. Results received by laser scanning method in 2012 - (TLS2012).

\begin{tabular}{|c|c|c|c|c|c|c|c|c|c|c|c|}
\hline \multirow{2}{*}{ Slices } & \multicolumn{3}{|c|}{ Center coordinates, $\mathrm{m}$} & \multicolumn{3}{|c|}{ Center shift, mm } & \multirow{2}{*}{$\begin{array}{l}\text { Direction angle } \\
\alpha^{\circ}\end{array}$} & \multicolumn{4}{|c|}{ Inclination from the vertical $(\beta)$} \\
\hline & $\mathrm{X}$ & Y & $\mathrm{H}$ & $\Delta \mathrm{X}$ & $\Delta \mathrm{Y}$ & $\Delta \mathrm{S}$ & & $\circ$ & $\circ$ & & " \\
\hline 1 & 6090237,651 & 553195,362 & 108,3 & - & - & - & - & - & - & - & - \\
\hline 2 & 6090237,699 & 553195,337 & 110,3 & 48 & -25 & 54 & 332 & 1,5508 & 1 & 33 & 2 \\
\hline 3 & 6090237,728 & 553195,329 & 111,3 & 77 & -33 & 84 & 337 & 1,5903 & 1 & 35 & 25 \\
\hline 4 & 6090237,818 & 553195,280 & 115,5 & 167 & -82 & 186 & 334 & 1,4666 & 1 & 27 & 59 \\
\hline 5 & 6090237,862 & 553195,265 & 116,5 & 211 & -97 & 232 & 335 & 1,6093 & 1 & 36 & 33 \\
\hline 6 & 6090237,955 & 553195,224 & 120,3 & 304 & -138 & 334 & 336 & 1,5931 & 1 & 35 & 35 \\
\hline $\mathrm{C}$ & 6090238,000 & 553195,274 & 124,0 & 349 & -88 & 360 & 345 & 1,3137 & 1 & 18 & 49 \\
\hline
\end{tabular}

Table 3. Results received by laser scanning method in 2013 - (LS2013).

\begin{tabular}{|c|c|c|c|c|c|c|c|c|c|c|c|}
\hline \multirow{2}{*}{ Slices } & \multicolumn{3}{|c|}{ Center coordinates, $\mathrm{m}$} & \multicolumn{3}{|c|}{ Center shift, $\mathrm{mm}$} & \multirow{2}{*}{$\begin{array}{l}\text { Direction angle } \\
\alpha^{\circ}\end{array}$} & \multicolumn{4}{|c|}{ Inclination from the vertical $(\beta)$} \\
\hline & $\mathrm{X}$ & $\mathrm{Y}$ & $\mathrm{H}$ & $\Delta \mathrm{X}$ & $\Delta \mathrm{Y}$ & $\Delta \mathrm{S}$ & & $\circ$ & o & ' & " \\
\hline 1 & 6090237,674 & 553195,345 & 108,3 & - & - & - & - & - & - & - & - \\
\hline 2 & 6090237,724 & 553195,322 & 110,3 & 50 & -23 & 55 & 331 & 1,5499 & 1 & 32 & 59 \\
\hline 3 & 6090237,753 & 553195,319 & 111,2 & 79 & -26 & 83 & 336 & 1,6174 & 1 & 37 & 2 \\
\hline 4 & 6090237,844 & 553195,256 & 115,5 & 170 & -89 & 192 & 334 & 1,5162 & 1 & 30 & 58 \\
\hline 5 & 6090237,893 & 553195,251 & 116,5 & 219 & -94 & 238 & 335 & 1,6649 & 1 & 39 & 53 \\
\hline 6 & 6090237,988 & 553195,210 & 120,3 & 314 & -135 & 342 & 336 & 1,6236 & 1 & 37 & 24 \\
\hline $\mathrm{C}$ & 6090237,947 & 553195,239 & 122,4 & 273 & -106 & 293 & 346 & 1,1864 & 1 & 11 & 11 \\
\hline
\end{tabular}

In the table above (Table 3) chapel deformation parameters from 2013 laser scanning measurements is presented. The maximum displacement of the center section is $34.2 \mathrm{~cm}$, and it gives inclination from the vertical by $1.6236^{\circ}$.

Table 4. Results received by total station in $2012-($ TS2012)

\begin{tabular}{|c|c|c|c|c|c|c|c|c|c|c|c|}
\hline \multirow{2}{*}{ Slices } & \multicolumn{3}{|c|}{ Center coordinates, $\mathrm{m}$} & \multicolumn{3}{|c|}{ Center shift, $\mathrm{mm}$} & \multirow{2}{*}{$\begin{array}{l}\text { Direction angle } \\
\alpha^{\circ}\end{array}$} & \multicolumn{4}{|c|}{ Inclination from the vertical $(\beta)$} \\
\hline & $\mathrm{X}$ & $\mathrm{Y}$ & $\mathrm{H}$ & $\Delta \mathrm{X}$ & $\Delta \mathrm{Y}$ & $\Delta \mathrm{S}$ & & $\circ$ & $\circ$ & ' & $"$ \\
\hline 1 & 6090237,633 & 553195,355 & 107,7 & - & - & - & - & - & - & - & - \\
\hline 2 & 6090237,693 & 553195,325 & 110,2 & 0 & 0 & 67 & 331 & 1,5559 & 1 & 33 & 21 \\
\hline 3 & 6090237,729 & 553195,322 & 111,2 & 60 & -30 & 102 & 336 & 1,6741 & 1 & 40 & 26 \\
\hline 4 & 6090237,820 & 553195,265 & 115,5 & 96 & -33 & 208 & 335 & 1,5296 & 1 & 31 & 46 \\
\hline 5 & 6090237,867 & 553195,261 & 116,4 & 187 & -90 & 252 & 335 & 1,6669 & 1 & 40 & 0 \\
\hline 6 & 6090237,960 & 553195,220 & 120,3 & 234 & -94 & 354 & 336 & 1,6155 & 1 & 36 & 55 \\
\hline
\end{tabular}

In the table (Table 4) above the results of 2012 total station measurements is presented .We can see only 6 cross-sections, because center of the cross is not evaluated in this dataset due to technical reasons. The maximum displacement of the center section is $35.4 \mathrm{~cm}$, and it gives inclination from the vertical of $1.6155^{\circ}$.

Table 5. Results received by total station in $2013-$ (TS2012)

\begin{tabular}{|c|c|c|c|c|c|c|c|c|c|c|c|}
\hline \multirow{2}{*}{ Slices } & \multicolumn{3}{|c|}{ Center coordinates, $\mathrm{m}$} & \multicolumn{3}{|c|}{ Center shift, mm } & \multirow{2}{*}{$\begin{array}{l}\text { Direction angle } \\
\alpha^{\circ}\end{array}$} & \multicolumn{4}{|c|}{ Inclination from the vertical $(\beta)$} \\
\hline & $\mathrm{X}$ & $\mathrm{Y}$ & $\mathrm{H}$ & $\Delta \mathrm{X}$ & $\Delta \mathrm{Y}$ & $\Delta \mathrm{S}$ & & $\circ$ & $\circ$ & , & " \\
\hline 1 & 6090237,652 & 553195,355 & 107,6 & - & - & - & - & - & - & - & - \\
\hline 2 & 6090237,716 & 553195,324 & 110,2 & 63 & -30 & 70 & 332 & 1,5308 & 1 & 31 & 50 \\
\hline 3 & 6090237,747 & 553195,321 & 111,1 & 94 & -34 & 100 & 336 & 1,6153 & 1 & 36 & 55 \\
\hline 4 & 6090237,840 & 553195,263 & 115,6 & 188 & -91 & 209 & 334 & 1,4988 & 1 & 29 & 55 \\
\hline 5 & 6090237,885 & 553195,260 & 116,4 & 233 & -95 & 251 & 335 & 1,6435 & 1 & 38 & 36 \\
\hline 6 & 6090237,982 & 553195,220 & 120,3 & 330 & -135 & 356 & 336 & 1,6040 & 1 & 36 & 14 \\
\hline $\mathrm{C}$ & 6090237,940 & 553195,224 & 122,1 & 288 & -130 & 316 & 346 & 1,2438 & 1 & 14 & 37 \\
\hline
\end{tabular}

In the table (Table 5) above the results of 2013 total station measurements is presented. The maximum displacement of the center section is $35.6 \mathrm{~cm}$, and it gives inclination from the vertical of $1.6040^{\circ}$. 
Table 6. Comparison of the results received by different devices

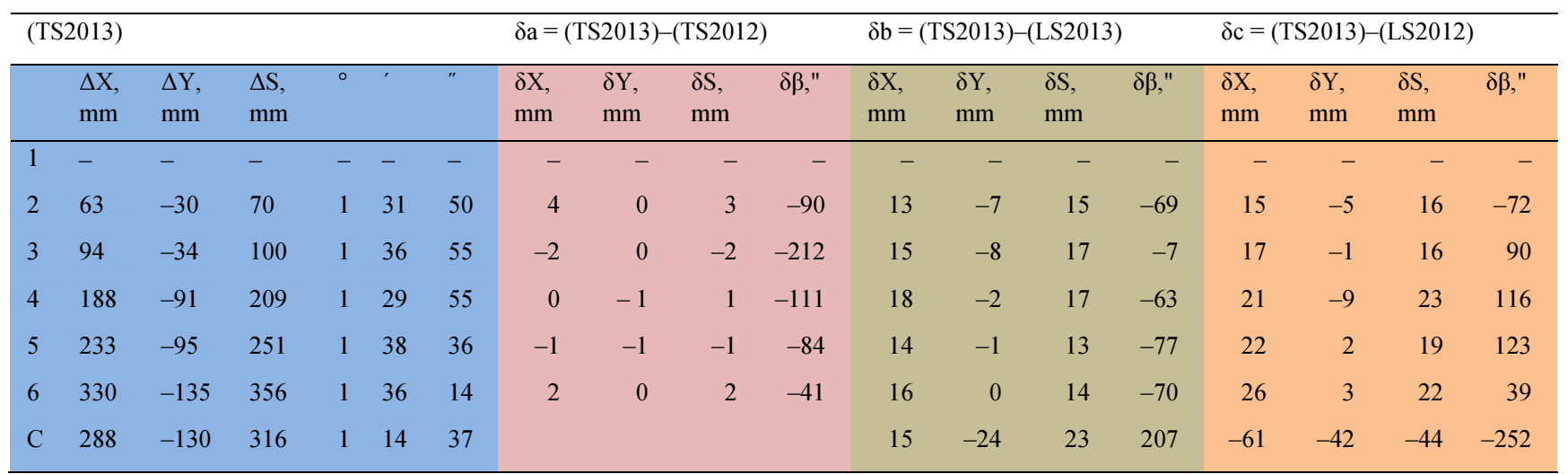

Main inclination parameters from 2013 total station measurements (TS2013), and their differences from the other year and other instrument (TLS) measurements are presented in Table 5. We see that the total station results from year 2012 and year 2103 cross-section center positions differs at only $4 \mathrm{~mm}$, but the difference of inclination is 212 ". The centers of the cross-sections from laser scanning by $26 \mathrm{~mm}$ and a maximum inclination mismatch is 123 ". It should be noted that the cross heel was not used in inclination determination because of its unstable structures). Based on the results it can be concluded that the average accuracy (about $5 \mathrm{~mm}$ ) of a laser scanner point cloud brings in average not much worse results than those treated with high-precision total station (about $1 \mathrm{~mm}$ ) measurements.

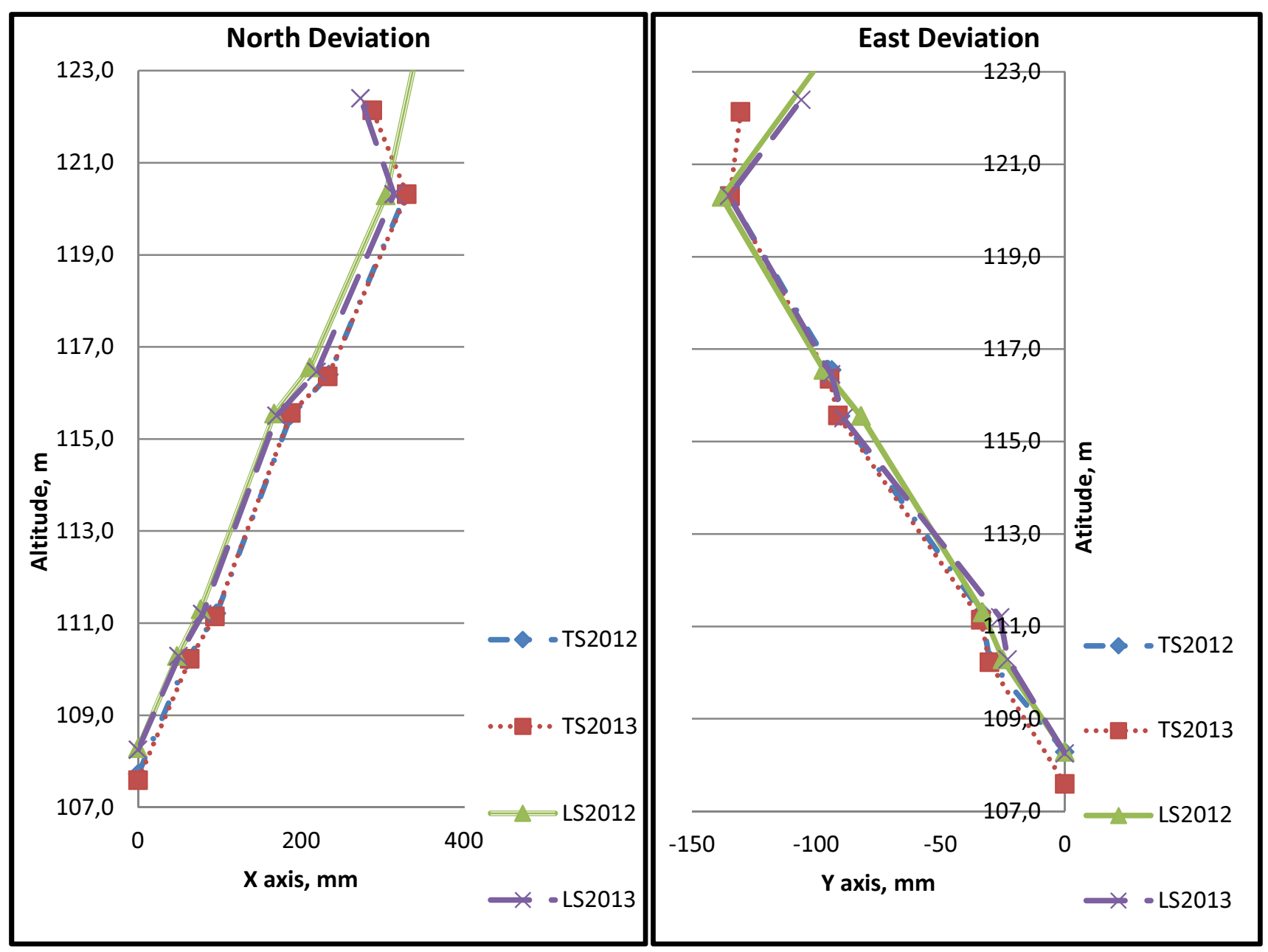

Fig. 2. Diagram of chapel inclinations obtained by terrestrial laser scanner and total station in 2012 and 2013

Figure 2 shows the displacement of the cross-section center in different heights. The left side of the figure displays an offset in $\mathrm{x}$-axis (north direction) expressed in millimetres. On the right side of the figure presents the displacement in the $\mathrm{y}$ axis (east direction). Heights are expressed in meters in the Baltic height system. 


\section{Conclusions}

1. Terrestrial laser measurement data processing is more complex and requires more time and technological resources, but the results are significantly more informative compared with the tachometer measurement data.

2. It can be concluded that three-dimensional model is suitable to perform engineering calculations and the accuracy of resulting values of the parameters of the object, corresponds to accuracy parameters achieved using classical precision surveying instruments.

3. From two sets of measurements, there is no significant change in inclination of St. Barbora Chapel observed during twelve month period. The estimated inclination angle of a chapel is $1.61^{\circ}$.

\section{References}

[1] Aksamitauskas, V. Č. 2011. Inžinieriniu statiniu deformaciju tyrimas geodeziniais metodais. Vilnius: Technika, 1-5.

[2] Bonora, V.; Cruciani Fabozzi, G.; Tucci, G. 2008. The use of 3D Scanning and Rapid Prototyping for the Documentation, Conservation and Communication of Archaeological Remains: a Recent Experience in the Sanctuary of S. M. del Lavello (Lecco, Italy), in Proceedings of the DMACH 2008 Conference "Digital Media and its Applications in Cultural Heritage”, Petra University, Amman, Giordania, 3-6 November 2008, 12-23. ISBN 978-9957-8602-5-7.

[3] Slattery, Dianne K.; Slattery, Kerry T. 2010. Evaluation of 3-D Laser Scaning for Constructions Application. Reserch Report ICT-10-068.

[4] Tucci, G.; Bonora, V. 2011. Geomatic techniques and 3D modeling for the survey of the Church of the Holy Sepulchre in Jerusalem, in Proceedings of the 23rd International CIPA Symposium, Prague, Czech Republic, September 12-16, 2011. ISBN 978-80-01-04885-6.

[5] Pfeifer, N.; Briese, C. 2007. Geometrical aspects of airborne laser scanning and terrestrial laser scanning, International Archives of Photogrammetry and Remote sensing 36(3): 311-319.

[6] Grussenmeyer, P.; Landes, T.; Voegtle, T.; Ringle, K. 2008. Comparison methods of terrestrial laser scanning, photogrammetry and tacheometry data for recording of cultural heritage buildings, Remote Sensing and Spatial Information Sciences 37: 213-218.

[7] García, J. L.; Van Genechten, B. 2008. Theory and practice on Terrestrial Laser Scanning, in Editorial de la Universidad June 2008 , p. 241. 